\title{
Energy Use of Fine Grinding in Mineral Processing
}

\begin{abstract}
JAN DE BAKKER
Fine grinding, to P80 sizes as low as $7 \mu \mathrm{m}$, is becoming increasingly important as mines treat ores with smaller liberation sizes. This grinding is typically done using stirred mills such as the Isamill or Stirred Media Detritor. While fine grinding consumes less energy than primary grinding, it can still account for a substantial part of a mill's energy budget. Overall energy use and media use are strongly related to stress intensity, as well as to media size and quality. Optimization of grinding media size and quality, as well as of other operational factors, can reduce energy use by a factor of two or more. The stirred mills used to perform fine grinding have additional process benefits, such as polishing the mineral surface, which can enhance recovery.
\end{abstract}

DOI: $10.1007 / \mathrm{s} 40553-013-0001-6$

(C) The Minerals, Metals \& Materials Society and ASM International 2013

\section{INTRODUCTION}

FINE grinding is becoming an increasingly common unit operation in mineral processing. While fine grinding can liberate ores that would otherwise be considered untreatable, it can entail high costs in terms of energy consumption and media use. These costs can be minimized by performing adequate test work and selecting appropriate operating conditions. This paper reviews fine grinding technology, research, and plant experience and seeks to shed light on ways in which operators can reduce both operating costs and the environmental footprint of their fine grinding circuit.

This paper will begin by giving an overview of fine grinding and the equipment used. It will then discuss energy-product size relationships and modeling efforts for stirred mills in particular. The paper will go on to cover typical test work requirements, the effect of media size, and the contained energy in media. In closing, specific case studies will be reviewed.

\section{ENERGY USE IN COMMINUTION}

Grinding activities in general (including coarse, intermediate, and fine grinding) account for 0.5 pct of U.S. primary energy use, 3.8 pct of total U.S. electricity consumption, and 40 pet of total U.S. mining industry energy use. Large energy saving opportunities have been identified in grinding in particular. ${ }^{1]}$

Table I shows a very large disparity between the theoretical minimum energy used in grinding and the actual energy used. More interestingly, a fairly large difference remains even between "Best Practice" grinding energy use and current energy use. This suggests that large savings in grinding energy (and associated savings in

JAN DE BAKKER, Metallurgist, is with BBA, Inc., 630 RénéLévesque Blvd. West, Suite 1900, Montreal, QC H3B 4V5, Canada. Contact e-mail: jan.debakker@bba.ca

Manuscript submitted April 25, 2013.

Article published online December 18, 2013 maintenance, consumables, and capital equipment needed) could be obtained by improving grinding operations.

As fine grinding is typically used on regrind applications, the feed tonnages to fine grinding circuits are small compared to head tonnages, typically 10 to $30 \mathrm{tph}$. However, the specific energies are often much larger than those encountered in intermediate milling and can be as high as $60 \mathrm{kWh} / \mathrm{t}$. Total installed power in a fine grinding circuit can range from several hundred $\mathrm{kW}$ to several MW; for example, the largest installed Isamill has $3 \mathrm{MW}$ installed power. ${ }^{[3]}$ This quantity is small compared to the power used by a semi-autogenous mill and a ball mill in a primary grinding circuit; a ball mill can have an installed power of up to $15 \mathrm{MW}$, while installed power for a SAG mill can go up to $25 \mathrm{MW}$. However, the energy used for fine grinding is still significant. Moreover, as this paper seeks to demonstrate, large energy reduction opportunities are frequently found in fine grinding.

\section{OVERVIEW OF FINE GRINDING}

Grinding can be classified into coarse, intermediate, and fine grinding processes. These differ in the equipment used, the product sizes attained, and the comminution mechanisms used. The boundaries between these size classes must always be drawn somewhat arbitrarily; for this paper, the boundaries are as given in Table II. As shown in the table, coarse grinding typically corresponds to using an AG or SAG mill, intermediate grinding to a ball mill or tower mill, and fine grinding to a stirred mill such as an Isamill or Stirred Media Detritor (SMD). Of course, various exceptions to these typical values can be found.

In fine grinding, a material with an F80 of less than $100 \mu \mathrm{m}$ is comminuted to a P80 of 7 to $30 \mu \mathrm{m}$. (P80s of $2 \mu \mathrm{m}$ are at least claimed by equipment manufacturers.) The feed is typically a flotation concentrate, which is reground to liberate fine particles of the value mineral.

The three modes of particle breakage are impact; abrasion, in which two particles shear against each other; and attrition, in which a small particle is sheared 
between two larger particles or media moving at different velocities. In fine grinding, breakage is dominated by attrition alone. ${ }^{[4]}$ In stirred mills, this is accomplished by creating a gradient in the angular velocity of the grinding media along the mill's radius.

\section{EQUIPMENT USED}

\section{A. High-Intensity Stirred Mills}

Fine grinding is usually performed in high-intensity stirred mills; several manufacturers of these stirred mills exist. Two frequently used stirred mills include the Isamill, produced by Xstrata Technology, and the SMD, produced by Metso (Figure 1). A third mill, the Knelson-Deswik mill (now the FLS stirred mill), is a relative newcomer to the stirred milling scene, having been developed through the 1990s and the early 2000s. ${ }^{[5]}$ In all these mills, a bed of ceramic or sand is stirred at high speed. Ceramic media sizes in use range from 1 to $6.5 \mathrm{~mm}$.

The Isamill and the SMD have very similar grinding performance. Grinding the same feed using the same media, Nesset et al. $^{[7]}$ found that the Isamill and SMD had very similar specific energy use. Gao et al. ${ }^{[8]}$ observed that an Isamill and SMD, grinding the same feed with the same media, produced very similar product particle size distributions (PSDs). This similarity in performance has also been observed in other operations.

Nevertheless, there are important differences. In the Isamill, the shaft is horizontal and the media are stirred by disks, while in the SMD, the stirring is performed by pins mounted on a vertical shaft. In an SMD, the

Table I. Energy Consumption in Total, in the Mining Industry, and in Grinding ${ }^{[1,2]}$

\begin{tabular}{ll}
\hline Category & $\begin{array}{l}\text { Energy Use } \\
\times 10^{9} \mathrm{kWh}\end{array}$ \\
\hline Total U.S. primary energy use (2011) & 28,509 \\
Total U.S. electricity consumption (after & 3856 \\
$\quad$ transmission and distribution losses, 2011) & \\
Total energy use in mining (2007) & 365 \\
Energy used in grinding activities (U.S. coal, & 145 \\
$\quad$ metals, and minerals mining, 2007) & \\
"Best Practice" energy use in grinding (U.S. coal, 123 \\
$\quad$ metals, and minerals mining, 2007) \\
$\begin{array}{l}\text { Theoretical minimum energy use in grinding } \\
\quad \text { (U.S. coal, metals, and minerals mining, }\end{array}$ \\
$\quad$ 2007)
\end{tabular}

product is separated from the media by a screen; the Isamill uses an internal centrifugation system. This means that the screens in an SMD constitute a wear part that must be replaced, while for the Isamill, the seals between the shaft and body constitute important wear parts. Liner changes and other maintenance are claimed by Xstrata Technology to be much easier than in an SMD: While an SMD's liner is removed in eight parts, the Isamill's liner can be removed in two pieces, with the shell sliding off easily. ${ }^{[3]}$ The Knelson-Deswik mill is top stirred and can therefore be considered to be similar to an SMD. ${ }^{[5]}$

An important difference among the Isamill, the SMD, and the Knelson-Deswik mill is that of scale. The largest Isamill installed at time of writing had $3 \mathrm{MW}$ of installed power; an $8 \mathrm{MW}$ Isamill is available, but appears not to have yet been installed. ${ }^{[3]}$ The largest SMD available has 1.1 MW of installed power; one 1.1MW SMD has been installed. The next largest size SMD has $355 \mathrm{~kW}$ of installed power. ${ }^{[6]}$ Thus, several SMDs are often installed for a fine grinding circuit, while the same duty would be performed by a single Isamill. SMDs are typically arranged in series, with the product of one becoming the feed for the other. This has the advantage that each SMD in the line can have its media and operating conditions optimized to the particle size of its particular feed. The largest installed power in a Knelson-Deswik mill is $699 \mathrm{~kW}^{[5]}$; this places it in an intermediate position between the $355-\mathrm{kW}$ and $1.1-\mathrm{MW}$ SMDs.

In 2012, FLSmidth reported that it had acquired the Knelson-Deswik mill; the mill is now known as the FLSmidth stirred mill. An FLSmidth stirred mill will be installed to perform a copper concentrate regrind in Mongolia. ${ }^{[9]}$ It is speculated that the mill will continue to be scaled up under its new owners to allow it to effectively compete against the SMD and Isamill.

\section{B. Fine Grinding in Gravity-Induced Stirred Mills and Ball Mills}

Gravity-induced stirred (GIS) mills include the Tower mill, produced by Nippon Eirich, and the Vertimill, produced by Metso. Grinding to below $40 \mu \mathrm{m}$ in GIS mills or ball mills is usually not recommended. In their product literature, Metso give $40 \mu \mathrm{m}$ as the lower end of the "optimal" P80 range for Vertimills. ${ }^{[6]}$ At lower product sizes, both tower mills and ball mills will overgrind fines. At Mt. Isa Mines, a GIS mill fed with material of F80 approximately $50 \mu \mathrm{m}$ lowered the P80 size by only 5 to $10 \mu \mathrm{m}$, at the same time producing a

Table II. Comminution Equipment, Size Classes, and Grinding Mechanisms

\begin{tabular}{llll}
\hline Grinding Level & Equipment & "Typical” P80 $(\mu \mathrm{m})$ & Dominant Breakage Mechanism* \\
\hline Coarse & AG/SAG mill & 500 to 10,000 & impact + abrasion + attrition \\
Intermediate & ball mill & 40 to 400 & impact + attrition \\
Fine & tower mill & 40 to 400 & attrition \\
& stirred mills & $<30$ & attrition
\end{tabular}

*See Ref. [4] 


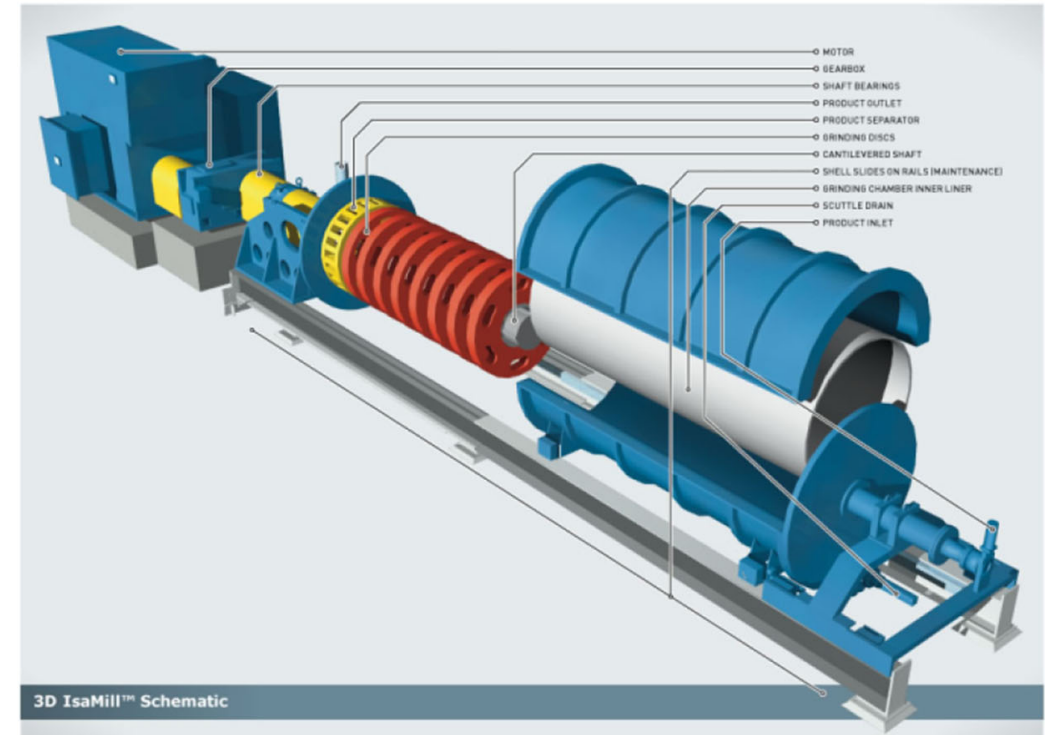

(a)

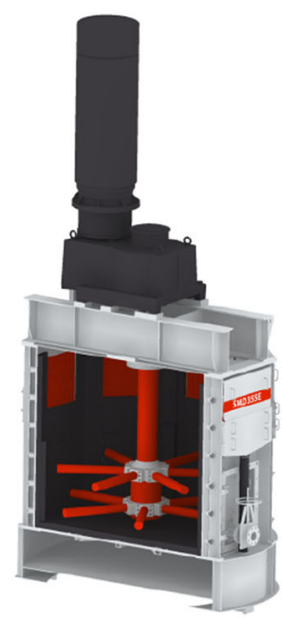

(b)

Fig. 1-Left: Isamill. ${ }^{[3]}$ Right: SMD ${ }^{[6]}$ Figures used with permission.

large amount of fines. ${ }^{[10]}$ Similarly, in ball mills, it is known that grinding finer than approximately $40 \mu \mathrm{m}$ will result in overgrinding of fines as well as high media consumption. However, it must be noted that the product size to which a mill can efficiently grind depends on the feed material, the F80, and media type and size. A Vertimill has been used to grind to sizes below $10 \mu \mathrm{m} \cdot{ }^{[11]}$

The phenomenon of overgrinding is largely the result of using media that are too large for the product size generated. The smallest ball size typically charged into ball mills and tower mills is $1 / 2$ inch $(12.5 \mathrm{~mm})$, although media diameters as small as $6 \mathrm{~mm}$ have been used industrially in Vertimills. ${ }^{[1]}$

In a laboratory study by Nesset et al. ${ }^{[7]}$ a GIS mill charged with 5-mm steel shot, and with other operating conditions similarly optimized, achieved high energy efficiencies when grinding to less than $20 \mu \mathrm{m}$. This appears to qualitatively confirm the notion that fine grinding requires smaller media sizes. In the case of the Nesset study, the power intensity applied to the laboratory tower mill was low-that is, the shaft was rotated slowly in order to obtain this high efficiency, leading to low throughput. This suggests that charging GIS mills with small media may not be practicable in plant operation.

\section{Millpebs}

Millpebs have been used as grinding media to achieve fine grinding in ball mills. These are 5- to $12-\mathrm{mm}$ spherical or oblong cast steel pellets, charged into ball mills as a replacement of, or in addition to, balls. While Millpebs can give significantly lower energy use when grinding to finer sizes, they also can lead to high fines production and high media use.
Millpebs were tested for fine grinding at the Brunswick concentrator. The regrind ball mills at the concentrator used $25-\mathrm{mm}$ slugs to produce a P80 of $28 \mu \mathrm{m}$. In one of the regrind mills, the slugs were replaced by Millpebs; these were able to consistently maintain a P80 of $22 \mu \mathrm{m}$ while decreasing the power draw by 20 pct. However, media use increased by 50 pct and the production of fines of less than $16 \mu \mathrm{m}$ diameter increased by a factor of $5 .^{[12]}$ The observed drop in specific energy may be due to the fact that Millpebs had smaller average diameters than the slugs and so were more efficient at grinding to the relatively small product sizes required. It is therefore unclear whether the performance of Millpebs would be better than that of conventional 12-mm steel balls. To the best of the author's knowledge, no performance comparison between Millpebs and similarly sized balls has been performed.

\section{Other Fine Grinding Technologies}

A host of other technologies exist to produce fine grinding, including jet mills, vibrating mills, roller mills, etc. However, none of these technologies has reached the same unit installed power as stirred mills. For example, one of the largest vibrating mills has an installed power of $160 \mathrm{~kW} \cdot{ }^{[13]}$ Therefore, these mills are considered as filling niche roles and are not treated further in this review. A fuller discussion of other fine grinding technologies can be found in a review by Orumwense and Forssberg. ${ }^{[14]}$

\section{E. Other Advantages to Stirred Milling}

Several advantages to stirred milling have been found apart from the efficient comminution of particles.

Neese et al. ${ }^{[15]}$ subjected 50 - to $150-\mu \mathrm{m}$ sand contaminated with oil to cleaning in a stirred mill in the 
laboratory. The mill operated at low stress intensities: A low speed and small-size media (200- to $400-\mu \mathrm{m}$ quartz or steel beads) were used. These conditions allowed the particles to be attrited without being broken. As a result, a large part of the oil contaminants was moved to the $-5-\mu \mathrm{m}$ portion of the product. This treatment may hold promise as an alternative means of processing bituminous sands, for example, in northern Alberta.

The Albion process uses ultrafine grinding to enhance the oxidation of sulfide concentrates in treating refractory gold ores. ${ }^{[16]}$ In the process, the flotation concentrate is ground to a P80 of 10 to $12 \mu \mathrm{m}$. The product slurry is reacted with oxygen in a leach tank at atmospheric pressure; limestone is added to maintain the $\mathrm{pH}$ at 5 to 5.5 . The leach reaction is autothermal and is maintained near the slurry boiling point. Without the fine grinding step, an autoclave would be required for the oxygen leaching process. It is hypothesized that the fine grinding enhances leach kinetics by increasing the surface area of the particles, as well as by deforming the crystal lattices of the particles.

Numerous researchers, for example, Buys et al., ${ }^{[17]}$ report that stirred milling increases downstream flotation recoveries by cleaning the surface of the particles. The grinding media used in stirred mills are inert, and therefore corrosion reactions, which occur with steel media in ball mills, are not encountered. Corrosion reactions change the surface chemistry of particles, especially with sulfide feeds, and hamper downstream flotation.

Further increases in flotation recoveries are obtained by limiting the amount of ultrafine particles formed; stirred mills can selectively grind the larger particles in the feed with little increase in ultrafines production. Ultrafine particles are difficult to recover in flotation.

\section{SPECIFIC ENERGY: PRODUCT SIZE RELATIONS}

\section{A. Validity Range of the Bond Equation}

In intermediate grinding to approximately $75 \mu \mathrm{m}$, the Bond equation (Eq. [1]) is used to relate feed size, product size, and mechanical energy applied. Below $75 \mu \mathrm{m}$, correction factors can be applied to extend its range of validity. ${ }^{[4]}$

$$
W=10 W_{i}\left[(\mathrm{P} 80)^{-0.5}-(\mathrm{F} 80)^{-0.5}\right]
$$

where $W$ is the specific grinding energy $(\mathrm{kWh} / \mathrm{t}), W_{i}$ is the Bond ball mill work index $(\mathrm{kWh} / \mathrm{t}), \mathrm{F} 80$ is the feed 80 pct passing size $(\mu \mathrm{m})$, and $\mathrm{P} 80$ is the product $80 \mathrm{pct}$ passing size $(\mu \mathrm{m})$.

It can be seen that in the regime in which the Bond equation is valid, energy use increases exponentially as product size decreases with constant feed size, with an exponent of (approximately) -0.5 .

For P80s finer than $75 \mu \mathrm{m}$, the Levin test, a modified Bond ball mill work index test, may be used to predict grinding performance. ${ }^{[18]}$

\section{B. Signature Plots}

No general work index formula governing energy use over a range of conditions, like the Bond equation for intermediate grinding, has yet been found for the fine grinding regime. Instead, the work-to-P80 curve is determined in the laboratory for each case. The energy use usually fits an equation of the form

$$
W=A(\mathrm{P} 80)^{k}
$$

where $W$ is the specific grinding energy $(\mathrm{kWh} / \mathrm{t}), \mathrm{P} 80$ the product 80 pct passing size $(\mu \mathrm{m})$, and $A$ and $k$ are the constants.

Taking the logarithm of both sides, one obtains a linear equation,

$$
\log W=\log A+k \cdot \log \text { P80 }
$$

and the specific energy vs P80 curve is usually plotted on $\log -\log$ axes. This is referred to as a "signature plot"; an example is given in Figure 2.

Values for the exponent $k$ have been found in the range -0.7 to -3.5 , meaning that the work to grind increases more rapidly as grind size decreases than in intermediate grinding. The specific energy vs product size curve has a much steeper slope in this region than in intermediate grinding.

The values of $k$ and $A$ are specific to the grinding conditions used in the laboratory tests. Changes in feed size, media size distribution, and in other properties such as media sphericity and hardness can change both $k$ and $A$, often by very large amounts. Media size and F80 appear to be the most important determinants of the signature plot equation.

The connections (if any) between $k$ and $A$ and various operating conditions remain unknown. Because of the relatively recent advent of stirred milling in mineral processing, fine grinding has not been studied to the same extent as grinding in ball mills (which of course entail much larger capital and energy expenditures in any case). One of the research priorities in the field of stirred milling should be the investigation of the effects of F80 and media size on the position of the signature plots. If analogous formulas to the Bond ball mill work formula and the Bond top ball size formula can be found, the amount of test work required for stirred milling would be greatly reduced.

\section{Surface Area Production Analysis}

Larson et al. ${ }^{[19]}$ found that when specific energy is plotted against the square of the percent particles in the product passing a given size (a proxy for particle surface area), a straight line is obtained. This is demonstrated in Figure 3.

In contrast to the conventional signature plot, this function gives zero energy at the mill feed. It is therefore hypothesized that if a squared function plot is obtained by test work for one feed particle size, the plot for another feed particle size can be obtained simply by changing the intercept of the line while keeping the slope the same. Therefore, the squared function plot allows the effect of changes in both F80 and P80 to be modeled. 


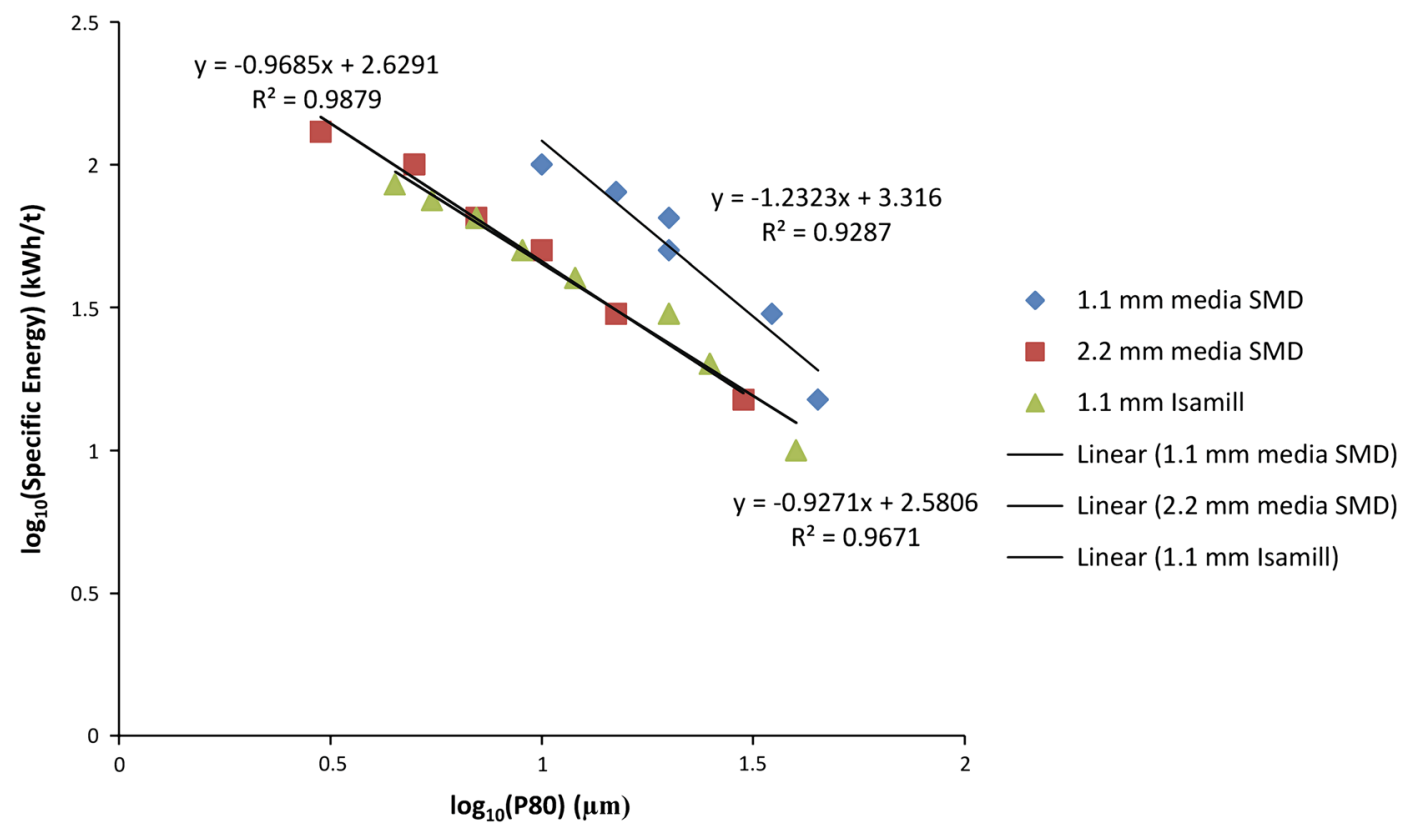

Fig. 2-Signature plot (specific energy vs P80 curve) for Brunswick concentrator $\mathrm{Zn}$ circuit ball mill cyclone underflow; F80 = $63 \mu \mathrm{m}$. The plots give results for grinding the same feed using different mills and media. After Nesset et al. ${ }^{[7]}$

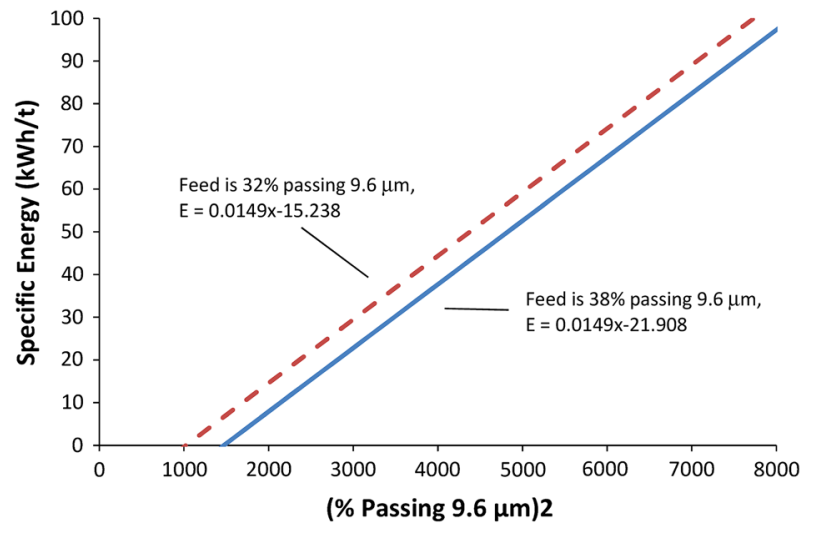

Fig. 3-"Squared function": specific energy is linear with the square of the percent passing a given size. After Larson et al. ${ }^{[19]}$

While the Squared Function Plot is intriguing, experimental validation of its applicability has not yet been published. It nevertheless remains an interesting topic for further investigation and if validated may be used in the future as an alternative measure of specific energy.

A similar analysis has been performed by Musa and Morrison, ${ }^{[21]}$ who developed a model to determine the surface area within each size fraction of mill product. They defined a "marker size" below which 70 to $80 \mathrm{pct}$ of the product surface area was contained; the marker size thus served as a proxy for surface area production. Specific energy use was then defined as $\mathrm{kWh}$ of power per the tonne of new material generated below the marker size. Musa and Morrison found that by defining specific energy in this way, it was possible to accurately predict the performance of full-scale Vertimills and Isamills from laboratory tests.

\section{STRESS INTENSITY}

\section{A. Overview}

Blecher and coworkers ${ }^{[22,23]}$ found that stress intensity combines the most important variables determining milling performance. Stress intensity for a horizontal stirred mill, with media much harder than the mineral to be ground, is defined as in Eq. [4].

$$
\mathrm{SI}_{\mathrm{s}}=D^{3}\left(\rho_{\mathrm{m}}-\rho_{\mathrm{s}}\right) v_{\mathrm{t}}^{2}
$$

where $\mathrm{SI}_{\mathrm{s}}$ is the stress intensity (stirring), $D$ the media diameter, $\rho_{\mathrm{m}}$ the media density, $\rho_{\mathrm{s}}$ the slurry density, and $v_{\mathrm{t}}$ is the impeller tip speed.

Note that the stress intensity is strongly sensitive to changes in media diameter (to the third power), is less sensitive to stirrer tip speed (to the second power), and is relatively insensitive to media and slurry density.

Jankovic $^{[24]}$ expanded the idea of stress intensity to include gravitational stress intensity:

$$
\mathrm{SI}_{\mathrm{g}}=D^{2}\left(\rho_{\mathrm{m}}-\rho_{\mathrm{s}}\right) g h
$$

where $\mathrm{SI}_{\mathrm{g}}$ is the stress intensity (gravitational), $g$ the gravitational acceleration, and $h$ is the media bed depth.

For vertical stirred mills such as the SMD and tower mill, both $\mathrm{SI}_{\mathrm{s}}$ and $\mathrm{SI}_{\mathrm{g}}$ are non-zero. For horizontal stirred mills such as the Isamill, net gravitational SI is zero due to symmetry along the horizontal axis. Therefore, for horizontal stirred mills, only $\mathrm{SI}_{\mathrm{s}}$ need be taken into consideration.

Kwade and coworkers noted that, at a given specific energy input, the product P80 obtainable varies with stress intensity and passes through a minimum. Product size at a given energy input can be viewed as a measure of milling efficiency; therefore, milling efficiency reaches a maximum at a single given stress intensity. This idea 
was experimentally validated by Jankovic and Valery (Figure 4). ${ }^{[25]}$

The stress intensity is defined by parameters that are independent of mill size or type. According to Jankovic and Valery, ${ }^{[25]}$ once the optimum SI has been determined in one mill for a given feed, the same SI should also be the point of optimum efficiency in any other mill treating that feed. Therefore, the optimum SI need only be determined in one mill (e.g., a small test mill); the operating parameters of a full-scale mill need only be adjusted to produce the optimum SI.

Stress frequency multiplied by stress intensity is equal to mill power; therefore, stress intensity could in theory be used to predict mill specific energy. However, to the author's knowledge, a comprehensive model linking stress intensity, stress frequency, and specific energy has not yet been developed. Therefore, there is not yet any direct link between stress intensity and specific energy.

\section{B. Effect of Media Hardness}

The definition of SIs as given in Eq. [4] is valid only for cases where the grinding media are much harder than that of the material ground (for example, the grinding of limestone with glass beads). Becker and Schwedes $^{[26]}$ determined that, in a collision between media and a mineral particle, the fraction of energy transferred to the product is given by Eq. [6]:

$$
E_{\mathrm{p}, \text { rel }}=Y_{\mathrm{m}} /\left(Y_{\mathrm{m}}+Y_{\mathrm{p}}\right)
$$

where $E_{\mathrm{p}, \text { rel }}$ is the fraction of energy transferred to product, $Y_{\mathrm{m}}$ the Young's modulus of media, and $Y_{\mathrm{p}}$ is the Young's modulus of the product.

To maintain high efficiency in milling, the media must be chosen so as to be much harder (higher Young's modulus) than the product material, keeping $E_{\mathrm{p}, \text { rel }}$ close to unity. Where the Young's modulus of the product is similar to that of the media, much of the applied energy goes into deformation of the media instead of that of the particle to be ground. The energy used to deform the media is lost, lowering the amount of energy transferred to the product. This fact explains why steel media, with a relatively low Young's modulus, tend to perform poorly in stirred milling, even though the media are much more dense than silica or alumina media.

Becker and Schwedes ${ }^{[26]}$ found that when grinding hard materials, a corrected stress intensity, $\mathrm{SI}_{\mathrm{p}}$, must be used:

$$
S I_{\mathrm{p}}=D^{3} \rho_{\mathrm{m}} v_{\mathrm{t}}^{2} /\left(1+Y_{\mathrm{p}} / Y_{\mathrm{m}}\right)
$$

\section{The Stress Intensity Scale-up Problem}

The previous sections indicated that stress intensity is independent from individual mills-i.e., the optimal stress intensity when using Mill A will also be the optimal stress intensity when using Mill B. However, this does not seem to be the case when actually scaling up mills.

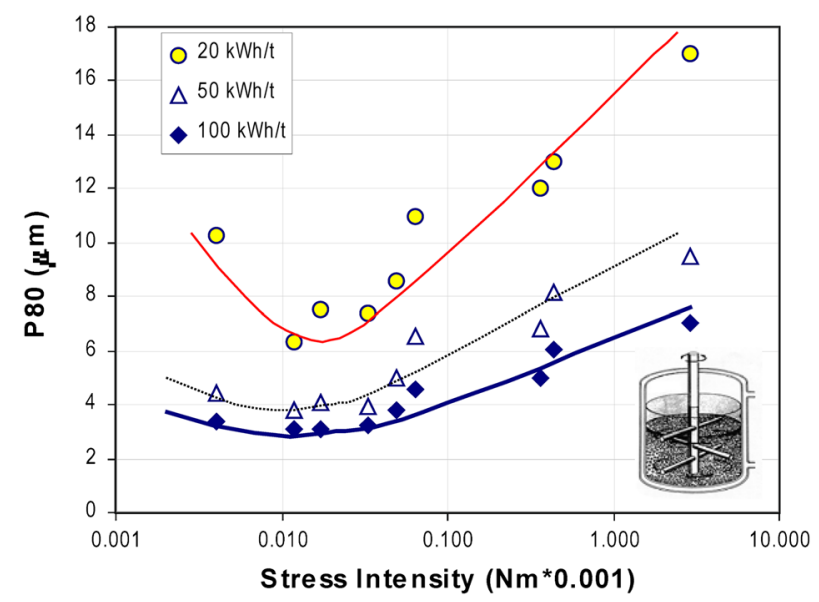

Fig. 4-Product size vs stress intensity at three different specific energies for a zinc regrind. Note optimum stress intensity at which the lowest product size is reached. Figure used with permission from Jankovic and Valery. ${ }^{[25]}$

Four-liter Isamills are commonly used for grindability test work. It can be assumed that operating parameters of the test mill (including media type, media size, and slurry density) are adjusted so far as possible to give the optimum SI. These parameters are then used in the fullscale mill as well. However, the 4 -L test mills have a tip speed of approximately $8 \mathrm{~m} / \mathrm{s}$, while full-scale Isamills have tip speeds close to $20 \mathrm{~m} / \mathrm{s}^{[27]}$ If the same media size, media density, and slurry density are used in the test mill as in the full-scale mill, the stress intensity of the full-scale mill will be approximately 6.25 times larger than that of the test mill. This implies that the full-scale mill is operating outside of the optimum SI and will be grinding less efficiently. That is to say that the operating point of the full-scale mill will be above the signature plot determined by test work.

In reality, however, the operating points of full-scale stirred mills are generally found to lie on the signature plots generated in test work. ${ }^{[19]}$ Therefore, the full-scale mills and test mills have the same milling efficiency, even though the full-scale mill operates at a different stress intensity than the test mill.

This question remains unresolved. One possible answer arises from the observation that two of the P80 vs SI curves in Figure 4 appear to have broad troughs, covering almost an order of magnitude change in SI. In this case, even a sixfold increase in SI might not create a noticeable difference in performance, considering experimental and measurement error.

The SMD test unit appears from photographs to have a bed depth of around $30 \mathrm{~cm}$, while the full-scale SMD355 has a bed depth of approximately one meter. This represents a change in the gravitational stress intensity of almost two orders of magnitude. As has been previously noted, however, laboratory and fullscale SMDs scale-up with a scale-up factor of approximately unity, with no apparent change in the optimum stress intensity. This observation suggests that the gravitational stress intensity, SIg, is unimportant in SMDs compared to the stirring stress intensity, SIs. By 
contrast, in GIS mills, where full-size units have bed depths of ten meters or more, gravitational stress intensity can be expected to be much more important in full-size units than in test units, adding a complicating factor to GIS mill scale-up.

\section{OTHER MODELING EFFORTS}

Factorial design experiments were performed by Gao et $a .^{[28]}$ and Tuzun and Loveday ${ }^{[29]}$ to determine the effect of various operating parameters on the power use of laboratory mills. Power models were determined giving the impact of different parameters as power equations with linear and nonlinear terms. The derived models did not appear to be applicable to mills other than the particular laboratory units being studied.

\section{TEST WORK}

In ball milling, the Bond ball mill work index can be used to determine specific energy at a range of feed and product sizes. The Bond top size ball formula can be used to estimate the media size required. No such standard formulas exist in fine grinding. Energy and media parameters must instead be determined in the laboratory for every new combination of operating conditions such as feed size, media size, and media type.

For the Isamill, test work is usually performed with a 4-L bench-scale Isamill. Approximately $15 \mathrm{~kg}$ of the material to be ground is slurried to 20 pct solid density by volume. The slurry is then fed through the mill and mill power is measured. The product's PSD is measured, additional water is added if needed, and the material is sent through the mill again. This continues until the target P80 is reached; typically, there will be 5 to 10 passes through the mill. The test work will produce a signature plot and media consumption data as the deliverables.

Test work for the SMD proceeds in a very similar fashion, except that a 1.4-L bench-scale SMD is used. Typically, approximately $500 \mathrm{~g}$ of sample is required.

In contrast to laboratory-scale testing for ball mills and AG/SAG mills, test work results for stirred mills can be used for sizing full-size equipment with a scale-up factor close to one. Larson et al. ${ }^{[19,20]}$ found a scale-up factor for the Isamill of exactly 1 , while Gao et al. ${ }^{[8]}$ imply that the scale-up factor for SMDs is 1.25.

A common error in test work is using monosize media (e.g., fresh 2-mm media loaded into in the mill) as opposed to "aged" media with a distribution of particle sizes. The aged media will grind the smaller feed particles more efficiently. Therefore, using "fresh" media will give a higher specific energy than in reality. ${ }^{[30]}$

Another pitfall is coarse holdup in the mill. If the mill is not sufficiently flushed, coarse particles will be kept inside the mill. The mill product then appears finer than it in reality is. This leads to lower estimates of specific energy than reality. ${ }^{[19]}$

Other sources of error in test work are reviewed in papers by Larson et al. ${ }^{[19,20]}$

\section{PARTICLE SIZE DISTRIBUTIONS}

In ball milling, the product particle size distribution (PSD) can usually be modeled as being parallel to the feed PSD on a log-linear plot. ${ }^{[4]}$ When grinding to finer sizes in ball mills, the parallel PSDs mean that large amounts of ultrafine particles are produced. This consumes a large amount of grinding energy while producing particles which are difficult to recover in subsequent processing steps such as flotation.

By contrast, stirred mills have been noted to produce a steeper product PSD than feed. This is illustrated in Figure 5.

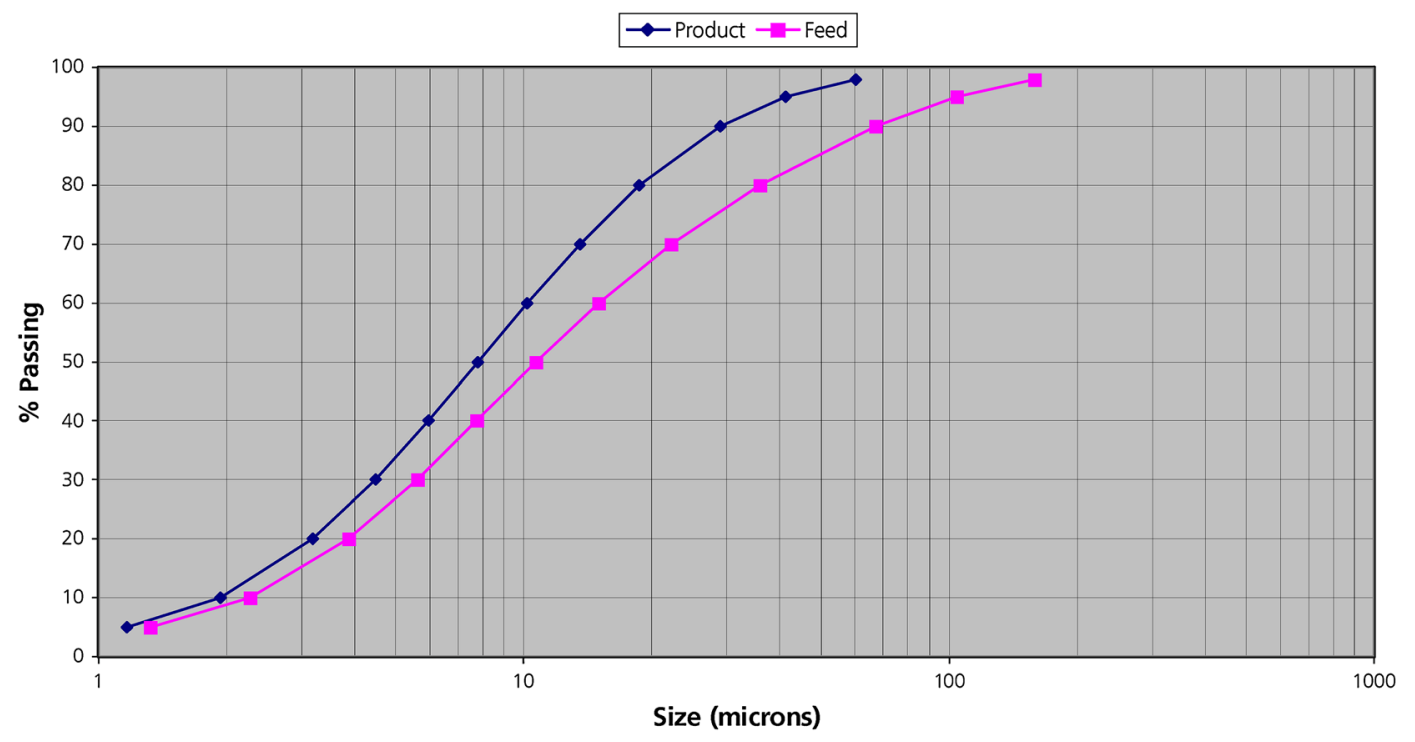

Fig. 5-Feed and product size distribution for an Isamill regrind at Cosmos mine, Australia. Figure used with permission from Curry et al. ${ }^{[31]}$ 
As shown in the figure, at the left end of the graph, the product PSD is very close to the feed PSD; at the right, the two PSDs are widely spaced. This indicates that the mill is efficiently using its energy to break the top size particles and is spending very little energy on further grinding of fine particles. Thus, the overall energy efficiency of the fine grinding can be expected to be good. As a bonus, the tighter PSD makes control of downstream processes such as flotation easier.

In an experimental study, Jankovic and Sinclair subjected calcite and silica to fine grinding in a laboratory pin stirred mill, a Sala agitated mill (SAM), and a pilot tower mill. The authors found that for each mill, the PSD of the product was narrower (steeper) than that of the feed. In addition, when grinding to P80s below approximately $20 \mu \mathrm{m}$ in any of the three mills tested, the PSD became more narrow (as measured by $\mathrm{P} 80 / \mathrm{P} 20$ ratio) as the $\mathrm{P} 80$ decreased. (When the width of the PSD was calculated using an alternative formula, the PSD was only observed to narrow with decreasing P80 when using the pin stirred mill.) The authors concluded that the width of the PSD was strongly affected by the material properties of the feed, while not being significantly affected by the media size used. ${ }^{[32]}$

\section{MEDIA USE AND CONTAINED ENERGY}

\section{A. Typical Media Use}

In stirred milling, the most commonly used media are ceramic balls of 1 to $5 \mathrm{~mm}$ diameter. The ceramic is usually composed of alumina, an alumina/zirconia blend, or zirconium silicate. Ceramic media exist over a wide range of quality and cost, with the lower quality/cost ceramic having a higher wear rate than higher quality/cost ceramic. Other operations have used sand as media, but at the time of writing, only two operations continue to use sand. ${ }^{[8,27,33]}$ Mt Isa Mines has used lead smelter slag as media; however, it is now using sand media. ${ }^{[10,27]} \mathrm{Mt}$ Isa is an exception in its use of slag, as a vast majority of operations do not have a smelter on-site to provide a limitless supply of free grinding media. However, in locations where slag is available, it should be considered as another source of media.

Media use in fine grinding is considered to be proportional to the mechanical energy applied. "Typical" wear rates and costs are given in Table III and Figure 6; these figures can of course vary significantly from operation to operation.

Of course, the choice of media type and quality will depend on media availability (in the case of sand and slag), wear rate, and price.

Jankovic and Valery ${ }^{[25]}$ reported that media comprise half of the operating cost for the SMDs at Century mine.

\section{B. Contained Energy in Media}

"Contained energy" refers to the energy required to produce and transport the media, and is distinct from the mechanical (electrical) energy used to drive the mill.
Table III. Wear Rates and Costs for Fine Grinding Media $^{[8,27,33-38]}$

\begin{tabular}{llc}
\hline Media Type & $\begin{array}{l}\text { Typical Wear } \\
\text { Rate }(\mathrm{g} / \mathrm{kWh})\end{array}$ & \multicolumn{1}{c}{ Cost $(\$ / \mathrm{t})$} \\
\hline Ceramic & 6 to 35 & 850 to 4500 \\
Sand & 50 to 177 & 100 to 250 \\
Silica-alumina-zirconia (SAZ) & "low" & 25,000 \\
Slag & as for sand? & - \\
\hline
\end{tabular}

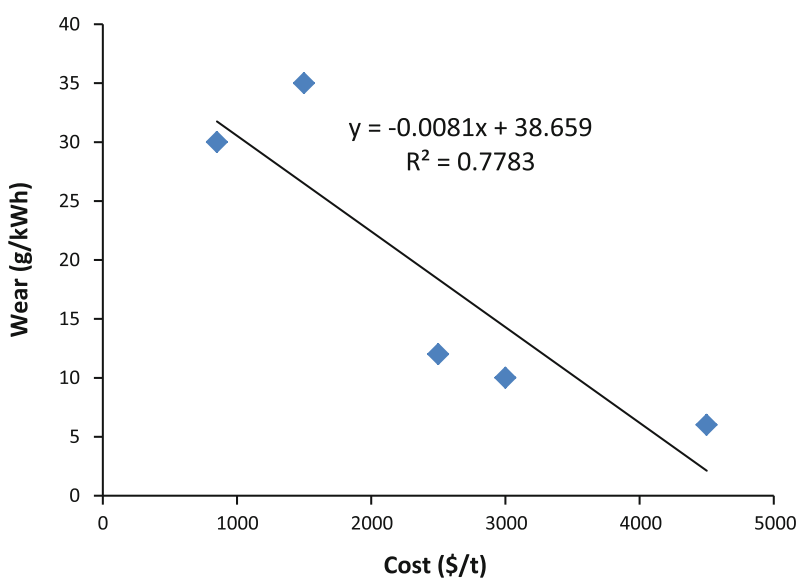

Fig. 6-Media price $v s$ wear. ${ }^{[8,26,31-36]}$

Hammond and Jones estimated the contained energy in household ceramics (not taking account of transportation). ${ }^{[39]}$ Hammond and Jones' estimates range from 2.5 to $29.1 \mathrm{MJ} / \mathrm{kg}$, with $10 \mathrm{MJ} / \mathrm{kg}$ for "general" ceramics and $29 \mathrm{MJ} / \mathrm{kg}$ for "sanitary" ceramics. Given that ceramic grinding media require very good hardness and strength, especially compared to household ceramics, it is appropriate to estimate its contained energy at the top end of Hammond and Jones' range, at $29 \mathrm{MJ} /$ $\mathrm{kg}$.

Using $29 \mathrm{MJ} / \mathrm{kg}$ for the contained energy of ceramic media and a wear rate of $35 \mathrm{~g} / \mathrm{kWh}$ of mechanical energy gives a contained energy consumption of $0.28 \mathrm{kWh}$ contained per $\mathrm{kWh}$ of mechanical energy applied. A wear rate of $7 \mathrm{~g} / \mathrm{kWh}$ gives a contained energy consumption of $0.06 \mathrm{kWh}$ contained per $\mathrm{kWh}$ of mechanical energy applied. Therefore, 6 to 20 pct of the energy use in fine grinding using ceramic media can be represented by "contained energy" in the grinding media itself.

Sand media have much lower contained energy than ceramic media as the media must simply be mined or quarried rather than manufactured. Hammond and Jones report a contained energy of $0.1 \mathrm{MJ} / \mathrm{kg}$. Blake et $a l .{ }^{[36]}$ reported that switching a stirred mill's media from sand to ceramic results in a mechanical energy savings of 20 pct. Therefore, using sand rather than ceramic media would produce savings in contained energy, but would cost more in mechanical energy. Likewise, Davey ${ }^{[40]}$ suggests that poor-quality media will increase mechanical energy use in stirred milling. It is speculated that this is due to the lower sphericity of 
sand media. On the other hand, the work of Nesset et al. ${ }^{[7]}$ suggests that the energy use between ceramic and sand media of the same size is the same. Slag media, where a smelter is on-site, would probably have the lowest contained energy consumption of the different media types. There is very little transportation, and for accounting purposes, almost no energy has gone into creating the media as the granulated slag is a by-product of smelter operation.

Becker and Schwedes ${ }^{[41]}$ point out that with poorquality media, a significant part of the product will consist of broken pieces of media, which will affect the measured product PSD. Clearly, more information on the relationships between contained energy in media and media wear rates is desirable.

\section{EFFECT OF MEDIA SIZE}

\section{A. Overview}

Of the different operating parameters for stirred mills, media size probably has the biggest influence on overall energy consumption. The appropriate media size for a mill appears to be a function of the F80 and P80 required. The grinding media must be large enough to break up the largest particles fed to the mill and small enough to grind the material to the product fineness desired. As demonstrated by the experience of Century mine, an inappropriate media size choice can result in energy consumption double that of optimum operation. $^{[8]}$

In their laboratory study, Nesset et al. ${ }^{[7]}$ varied a number of operating parameters for stirred mills and identified media size as having the largest impact on energy use. It was also noted that the trials which produced the sharpest product PSD were also the ones which resulted in the lowest specific energy use.

Gao et al. ${ }^{[8]}$ report that at Century mine, the grinding media in SMDs performing regrind duty were changed from 1 to $3 \mathrm{~mm}$. This resulted in a drop in energy use of approximately $50 \mathrm{pct}$; the signature plot shifted significantly downward (Figure 7).

Figure 8 shows the product PSD for laboratory SMD tests using 1- and 3-mm media. The PSD for the test using $1-\mathrm{mm}$ media shows that the SMD produced a significant amount of fines (20 pct below $4 \mu \mathrm{m})$. The mill also had difficulty breaking the top size particles - the 100 pct passing size appears to be almost the same for both the feed and the product. In contrast, the PSD using 3-mm media shows less fines production (20 pct below $9 \mu \mathrm{m}$ ) and effective top size breakage, with all the particles above $90 \mu \mathrm{m}$ broken. This is in line with the observation of Nesset et al. ${ }^{[7]}$ that low energy use is associated with tight product size distributions.

Mount Isa Mines achieved approximately $25 \mathrm{pct}$ savings in mechanical energy when it screened the $-0.5-\mathrm{mm}$ fraction of the lead smelter slag it used as media. ${ }^{[10]}$

Gao et al. ${ }^{[38]}$ tested copper reverberatory furnace slag (CRFS, SG 3.8) and heavy media plant rejects (HMPR, SG 2.4) in a laboratory stirred mill at two sizes: $-0.8 /$

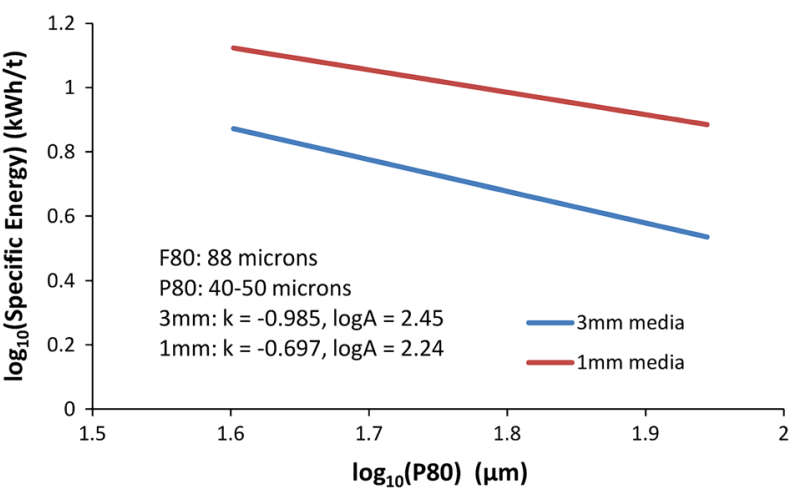

Fig. 7- Signature plots for SMDs at Century mine using 1-mm ceramic media (in red, higher) and 3-mm media (in blue, lower) (after Gao et al. ${ }^{[8]}$ ) (Color figure online).

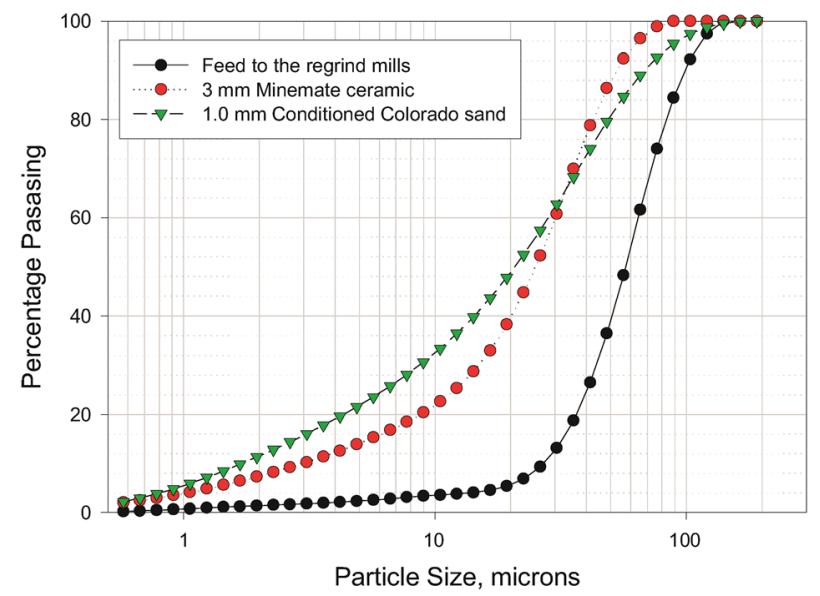

Fig. 8-Product size distributions for laboratory SMDs at Century mine using 1- and 3-mm media. Figure used with permission from Gao et al. ${ }^{[8]}$

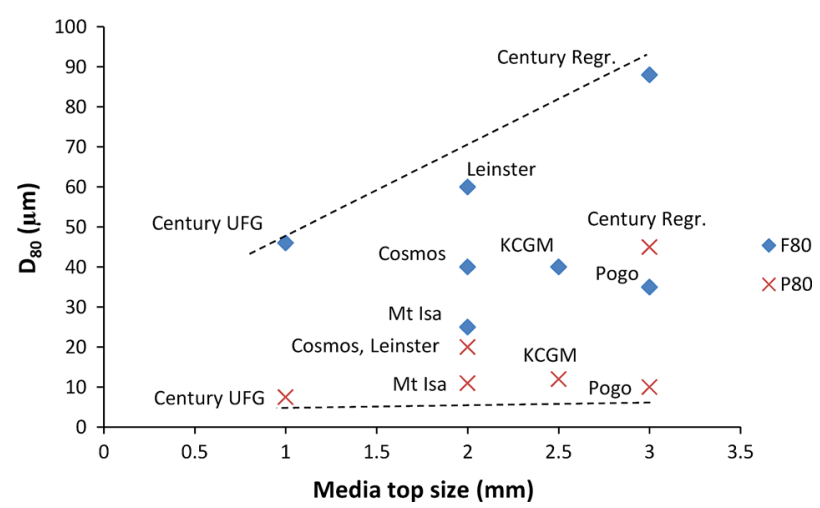

Fig. 9-F80 plotted against media size (blue diamonds); P80 plotted against media size (red crosses). Century UFG $=$ Century ultrafine grind; Century Regr. = Century regrind. Data are taken from Case studies table (Color figure online).

$+0.3 \mathrm{~mm}$, and $-1.7 /+0.4 \mathrm{~mm}$. For both CRFS and HMPR, the smaller size media gave a lower specific energy than the larger size media. At the same size, both CRFS and HMPR had similar specific energy use. 


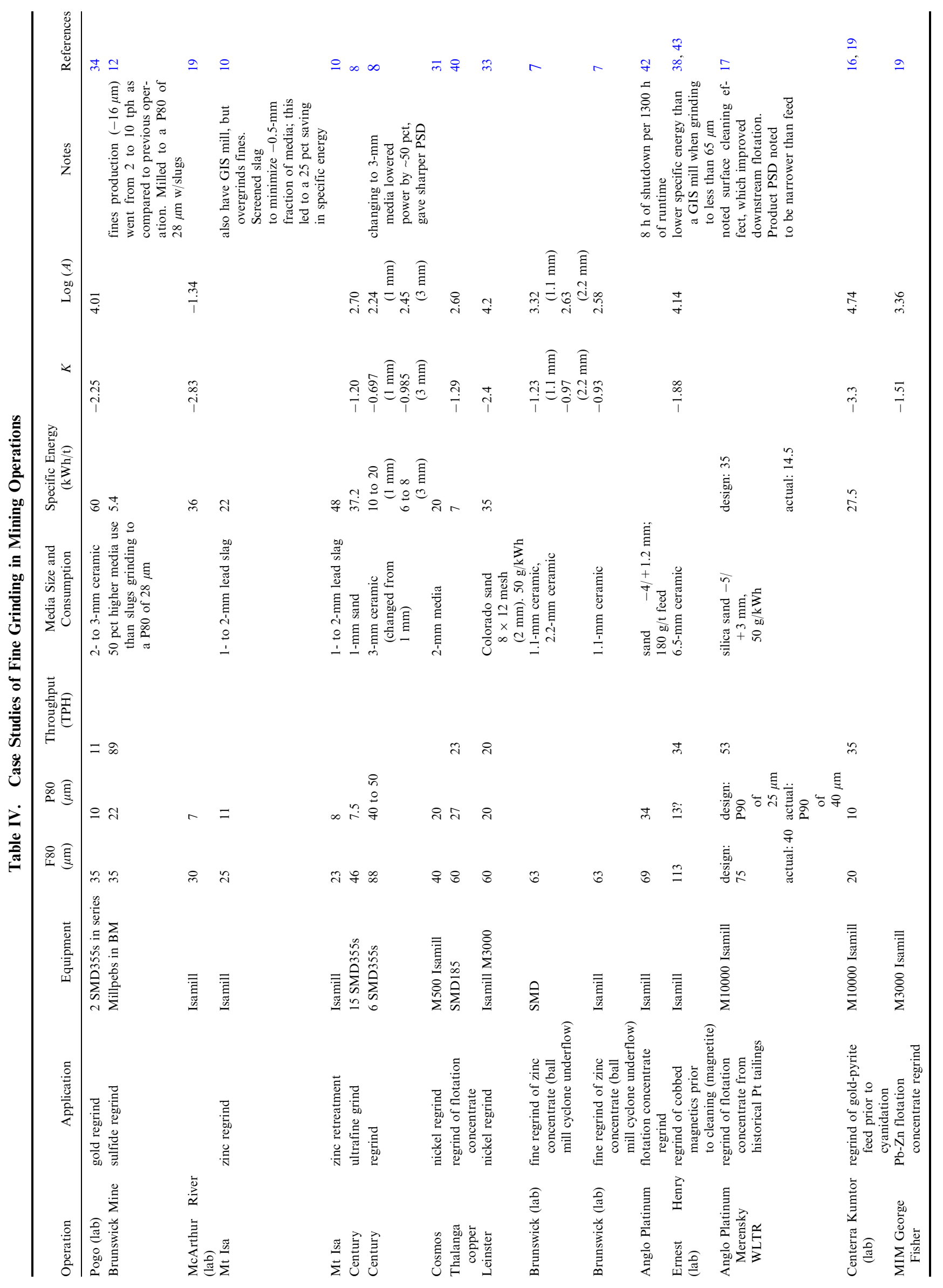




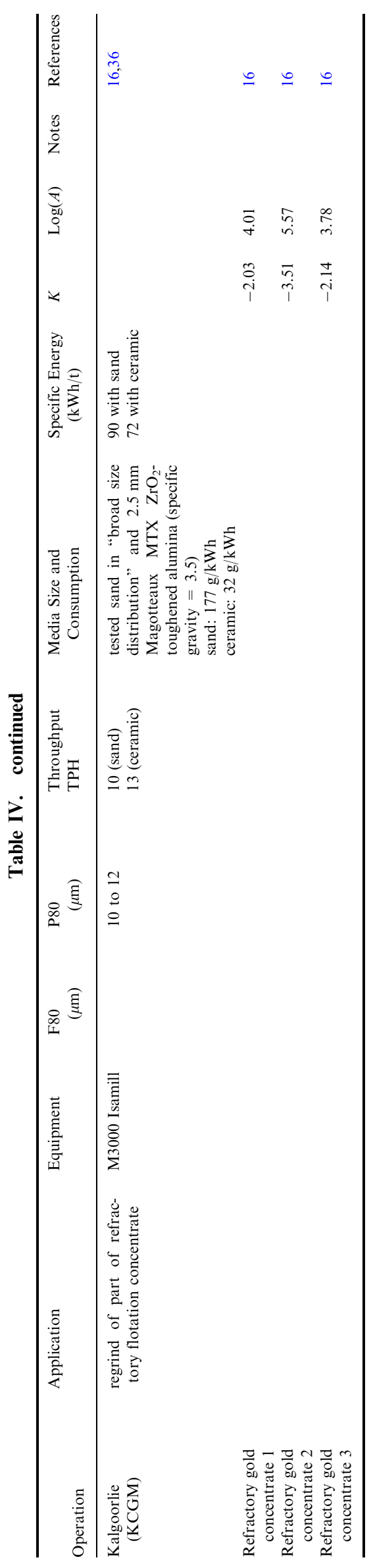

However, the CRFS ground the material much faster than HMPR. Possibly, this was due to its higher density.

\section{B. Media Size Benchmarking}

Data on F80, P80, and media size were compiled from the literature in order to allow benchmarking against existing operations. The sources are listed in Table IV. F80 and P80 were plotted against media size; the results are given in Figure 9.

It can be seen from the figure that as the P 80 achieved decreases, the media size does as well, from $3 \mathrm{~mm}$ to achieve $45 \mu \mathrm{m}$ to $1 \mathrm{~mm}$ to achieve under $10 \mu \mathrm{m}$. The F80 decreases with media size in a similar way, from $90 \mu \mathrm{m}$ at $3 \mathrm{~mm}$ to $45 \mu \mathrm{m}$ at $1 \mathrm{~mm}$. Dotted lines have been added to Figure 7 to define the region of operation of mills; these delimit a zone in which the stirred mill can be expected to operate efficiently.

In general, for a particular media size, limits on both F80 and P80 must be respected. For example, the figure suggests that a mill operating with an F80 of $100 \mu \mathrm{m}$ should use $3-\mathrm{mm}$ media, while a mill grinding to below $10 \mu \mathrm{m}$ would need to use $1-\mathrm{mm}$ media. To reduce a feed of $90 \mu \mathrm{m} \mathrm{F} 80$ to $10 \mu \mathrm{m}$ P80, Figure 9 suggests that comminution be done in two stages (two Isamills or SMDs in series) for optimal efficiency. The first stage would grind the feed from $90 \mu \mathrm{m}$ to perhaps $45 \mu \mathrm{m}$ using $3-\mathrm{mm}$ media, while the second would grind from 45 to $10 \mu \mathrm{m}$ using 1 - or $2-\mathrm{mm}$ media.

\section{CASE STUDIES}

A short summary of case studies of fine grinding given in the literature is presented in Table IV.

\section{OPPORTUNITIES FOR ENERGY REDUCTION}

A number of opportunities exist to reduce the energy footprint of fine grinding mills. There are no general formulas, such as the Bond work formula and Bond top size ball formula in ball milling, to describe the performance of stirred mills. Therefore, improvement opportunities must be quantified by performing appropriate test work.

\section{A. Stress Intensity}

Test work should be performed to identify the optimum stress intensity. This may provide the lowest specific energy for fine grinding.

\section{B. Specific Energy vs New Surface Area}

In addition to obtaining the signature plot, the specific energy as a function of new surface area should be determined during test work. This could be done either by the method of Larsen or by that of Musa and Morrison. Defining specific energy as a function of new surface area may constitute a superior means of pre- 
dicting the performance of full-scale mills, as opposed to defining specific energy as a function of feed tonnage.

\section{Media Size}

Media size should be chosen with care. It is recommended that test work be done with several media sizes in order to locate the stress intensity optimum. Media size can be benchmarked against other operations using Figure 9.

\section{Media Quality and Type}

There are indications that lower-quality media, apart from degrading faster, require more mechanical energy for grinding due to factors such as lower sphericity. It is recommended to perform test work using media of different quality to determine the effect of media quality on energy use. Slag and sand media may also be considered. Subsequently, a trade-off study involving media cost, electricity cost, improvement in energy efficiency, and contained energy in media should be performed to identify the best media from an economic and energy footprint standpoint.

\section{REFERENCES}

1. BCS/U.S. Department of Energy Industrial Technologies Program: Mining Industry Energy Bandwidth Study, 2007, available at http://www1.eere.energy.gov, accessed April 2013.

2. U.S. Energy Information Administration: Annual Energy Review 2011, DOE/EIA-0384(2011), 2012.

3. Xstrata Technology: Isamill Website, 2013, available at http://www. isamill.com, accessed April 2013.

4. T.J. Napier-Munn, S. Morell, R.D. Morrison, and T. Kojovic: Mineral Processing Circuits: Their Operation and Optimisation, Julius Kruttschnitt Mineral Research Centre, Indoorpilly, QLD, 1999.

5. D. Rahal, D. Erasmus, and K. Major: Knelson-Deswick Milling Technology: Bridging the Gap Between Low and High Speed Stirred Mills, Paper presented at the 43rd Canadian Mineral Processors Meeting, Ottawa, 2011.

6. Metso: Stirred milling: Vertimill grinding mills and Stirred Media Detritor (product brochure), 2013, available at http://www.metso. com/miningandconstruction/MaTobox7.nsf/DocsByID/F5868042 7E2A748F852576C4005210AC/SFile/Stirred_Mills_Brochure-2011_ LR.pdf, accessed April 21, 2013.

7. J. Nesset, P. Radziszewski, C. Hardie, and D. Leroux: Assessing the Performance and Efficiency of Fine Grinding Technologies, Paper presented at the 38th Canadian Mineral Processors Meeting, Ottawa, 2006.

8. M. Gao, L. Reemeyer, D. Obeng, and R. Holmes: 9th Mill Operators' Conference, Fremantle, Australia, 19-21 March 2007, pp. 105-09.

9. FLSmidth: Acquisition enhances our precious metals offerings, 2012, FLSmidth eHighlights April 2012, available at http://www. flsmidth.com/en-US/eHighlights/Archive/Minerals/2012/April/ Acquisition + enhances + our + precious + metals + offerings, accessed 17 April 2013

10. M. Gao, M. Young, and P. Allum: IsaMill Fine Grinding Technology and Its Industrial Applications at Mt Isa Mines, Paper presented at the 34th Canadian Mineral Processors Meeting, Ottawa, 2002.
11. J. Allen: Personal Communication, 2013.

12. I. Orford, P. Lacoste-Bouchet, and M. Cooper: Millpebs Testing at Brunswick Concentrator, Paper presented at the 38th Canadian Mineral Processors Meeting, Ottawa, 2006.

13. K. Andres and F. Haude: J. S. Afr. Inst. Min. Metall., 2010, vol. 110 , pp. $125-31$.

14. O.A. Orumwense and E. Forssberg: Miner. Process. Extr. Metall. Rev., 1992, vol. 11, pp. 107-27.

15. T. Neesse, F. Schaaff, and H. Tiefel: Miner. Eng., 2004, vol. 17, pp. 1163-67.

16. D.W. Turner and M. Hourn: Albion Process for Treatment of Refractory Ores, Paper presented at ALTA 2010, Perth, Australia, 2010.

17. S. Buys, C. Rule, and D. Curry: The Application of Large Scale Stirred Milling to the Retreatment of Merensky Platinum Tailings, Paper presented at the 37th Canadian Mineral Processors Meeting, Ottawa, 2005.

18. J. Levin: J. S. Afr. Inst. Min. Metall., 1989, vol. 89 (1), pp. 13-21.

19. M. Larson, G. Anderson, R. Morrison, and M. Young: Regrind Mills: Challenges of Scaleup, Paper presented at SME Annual Meeting, Feb 27-Mar 2, Denver, CO, 2011.

20. M. Larson, G. Anderson, K. Barns, and V. Villadolid: IsaMill 1:1 Direct Scaleup from Ultrafine to Coarse Grinding, Paper presented at Comminution 2012, 2012.

21. F. Musa and R. Morrison: Miner. Eng., 2009, vol. 22, pp. 593-601.

22. L. Blecher, A. Kwade, and J. Schwedes: Powder Technol., 1996, vol. 86 , pp. $59-68$.

23. A. Kwade, L. Blecher, and J. Schwedes: Powder Technol., 1996, vol. 86 , pp. $69-76$.

24. A. Jankovic: Miner. Eng., 2001, vol. 14 (10), pp. 1177-86.

25. A. Jankovic and W. Valery: Proc. 6th IIR Crushing and Grinding Conference, Perth, Australia, 29-30 March 2005.

26. M. Becker, A. Kwade, and J. Schwedes: Int. J. Miner. Process., 2001, vol. 61 (3), pp. 189-208.

27. M. Larson: Personal Communication, 2013.

28. M. Gao, K. Forssberg, and K. Weller: Int. J. Miner. Process., 1996, vols. 44-45, pp. 641-52.

29. M. Tuzun and B. Loveday: Miner. Eng., 1994, vol. 7 (5-6), pp. 551-60.

30. M. Brissette: Personal Communication, 2013.

31. D. Curry, M. Cooper, J. Rubenstein, T. Shouldice, and M. Young: The Right Tools in the Right Place: How Xstrata Nickel Australasia Increased Ni Throughput at Its Cosmos Plant, Paper presented at the 42nd Canadian Mineral Processors conference, Ottawa, 2010.

32. A. Jankovic and S. Sinclair: Miner. Eng., 2006, vol. 19, pp. 1528-36.

33. D.R. Seaman, K. Barns, P. Sharman, S. Thomas, and K. Stokes: Ninth Mill Operator's Conference, 2007, Fremantle WA, pp. 131-37.

34. G. Davey: Fine Grinding Applications Using the Metso Vertimill Grinding Mill and the Metso Stirred Media Detritor (SMD) in Gold Processing, Paper presented at the 38th Canadian Mineral Processors Meeting, Ottawa, 2006.

35. B. Knorr and J. Allen: Selection Criteria of Stirred Milling Technologies, Paper presented at Comminution '10, Cape Town, South Africa, 2010.

36. G. Blake, C. Gianatti, and B. Clermont: AusIMM Bull., 2012, vol. 4 , pp. $38-42$.

37. D.C. Curry and B. Clermont: Improving the Efficiency of Fine Grinding-Developments in Ceramic Media Technology, Paper presented at the Randol Conference, 2005.

38. M. Gao, M. Young, B. Cronin, and G. Harbort: Miner. Metall. Process., 2001, vol. 18 (2), pp. 117-20.

39. G. Hammond and C. Jones: Inventory of Carbon and Energy V1.6a, University of Bath, Bath, U.K., 2008.

40. G. Davey: Ultrafine and Fine Grinding Using the METSO Stirred Media Detritor (SMD), Paper presented at the 34th Canadian Mineral Processors meeting, Ottawa, 2002.

41. M. Becker and J. Schwedes: Powder Technol., 1999, vol. 103 (1-3), pp. 374-81.

42. A.K. Anyimadu, C.M. Rule, and L. Knopjes: J. S. Afr. Inst. Min. Metall., 2007, vol. 107, pp. 15-22.

43. J. Siliezar, D. Stoll, and J. Twomey: Unlocking the Value in Waste and Reducing Tailings: Magnetite Production at Ernest Henry Mining, Paper presented at Iron Ore 2011, Perth, WA, 2011. 